\title{
$\operatorname{arCOS} D E S I G N$
}

\section{"Rio Comprido em Nós": do espaço público à construção do público por meio do design}

Mariana Costard (ESDI/UERJ, Brasil)

marianacostard@gmail.com

Instituição: Escola Superior de Desenho Industrial, Universidade Estadual do Rio de Janeiro (ESDI/UERJ)

Endereço: Rua do Passeio, 80 - Centro - Rio de Janeiro 


\title{
"Rio Comprido em Nós": do espaço público à construção do público por meio do design
}

Resumo: 0 presente artigo vai buscar articulações entre a minha pesquisa em desenvolvimento com o tema da mesa "Expansões do design: possíveis comuns urbanos" do Seminário Design.COM. Iniciada no mestrado com projeto sobre o espaço público urbano, a investigação acaba por estender seu foco para as questões de interesse público e as possibilidades de atuação do design, por meio de suas ferramentas e métodos, para uma construção mais democrática das cidades. A partir da abordagem do Participatory Design e do Design Anthropology, relato parte do projeto realizado no bairro do Rio Comprido, Rio de Janeiro, como experimentação prática dos assuntos teóricos aqui abordados e seus transbordamentos no âmbito do doutorado para o planejamento urbano e as políticas públicas.

Palavras-chave: Co-design, design anthropology, espaço público, políticas públicas, planejamento urbano.

\section{"Rio Comprido em Nós": from public space to the construction of public by means of design}

\begin{abstract}
The present article seeks links between my developing research and the theme that has been discussed at the table "Expansions of design: possible urban common" of the Seminar Design.COM. The research was initiated in my master's degree's project on the urban public space. It ends up focusing on issues of public interest and possibilities for design discipline to contribute for a more democratic construction of cities through its tools and methods. Based on Participatory Design and Design Anthropology's approaches, I report part of the project carried out in Rio Comprido (a neighborhood in Rio de Janeiro) as a practical experience of theoretical subjects. I also recognize possible connections with the fields of urban planning and public policies.
\end{abstract}

Keywords: Codesign, design anthropology, public space, public policies, urban planning. 


\section{Do espaço público à construção do público por meio do design}

A investigação iniciada no mestrado e continuada atualmente no doutorado teve como motivação os interesses pessoais de melhoria do espaço público, especificamente o bairro onde nasci e vivi por quase toda a vida, articulados com as possibilidades de contribuição do design nesse processo. Para tanto, busquei um entendimento multidisciplinar sobre a construção do espaço público urbano, desde sua formação histórica e política à percepção mais sutil de elementos influentes em sua configuração dinâmica. Assumo-o como um dispositivo (FoUCAULT, 1979): um sistema multilinear com diferentes dimensões em interação constante, diversidade de representações e identidades heterogêneas, com articulações estratégicas em um jogo de disputas e poderes.

As formulações de Henri Lefebvre foram importantes para refletir sobre a "produção do espaço" (LeFEBVRE, 2000) a partir de suas práticas sociais, percebendo uma dimensão antropológica no processo de viver, perceber e conceber o espaço. Entendendo que o espaço é vivido antes de ser percebido, adentra dimensões mais subjetivas da vida social cotidiana e se posiciona à margem de teorias urbanas generalistas baseadas em grandes obras (SILVANO, 2010). Também é autor de "o direito à cidade" (Lefebvre, 2008), sobre o qual David Harvey (2014) se posiciona pela necessidade de reivindicar o poder coletivo de representação na construção e reinvenção das cidades, visto que seu processo histórico está associado à acumulação de excedentes de produção, polarização na distribuição de riqueza e poder, em ligação íntima com o desenvolvimento do capitalismo. A "produção capitalista do espaço" (HARVEY, 2014) priorizou os interesses econômicos aos humanos e gerou um território urbano consumista com desigualdade de participação e exclusão social, concentração de pobreza, em movimentos de desapropriação, privatização e gentrificação.

Em resposta ao aumento progressivo da população das cidades e suas transformações, operações urbanas foram implementadas de forma homogeneizante, sem considerar suas especificidades culturais locais e práticas sociais. Projetos de revitalização e requalificação recentes estão associados a um tipo de planejamento estratégico que acabam por intensificar as desigualdades sociais e a produção de um território excludente, através de parcerias público-privadas que buscam recuperar espaços degradados e gerar novas dinâmicas sociais, atraindo moradores e usuários com maior poder aquisitivo e transformando os lugares em objeto de consumo, com consequente exclusão da população de baixa renda (MAGNANI, 2002). De acordo com Carlos Vainer (2000), o modelo de planejamento urbano difundido no Brasil é transposto do planejamento empresarial, que pensa as cidades como empresas em concorrência em um mercado internacional. As "cidades-empresa" e "cidadesmercadoria" são construídas a partir da apropriação do capital, da valorização 
imobiliária e da privatização dos espaços públicos, em sucessivos processos de segregação e homogeneização (VAINER, 2002).

Esse panorama indica a necessidade de se refletir sobre a construção das cidades e dos espaços públicos urbanos e as consequências sociais e políticas de decisões projetuais. Já em 1961, Jacobs criticava os fundamentos do planejamento e da reurbanização vigentes (JACOBS, 2000), baseados em princípios e objetivos modernos e ortodoxos. Convencida que as cidades são um imenso laboratório de construção e desenho, em que especialistas e teóricos do planejamento urbano deveriam aprender, elaborar e testar suas teorias, sugeria que eles deixassem de ignorar o cotidiano das cidades reais pois a mera aplicação de suas teorias prontas acabariam por saquear as cidades, expropriar pessoas e comunidades e destruir pequenos negócios. Defendia a diversidade como meio capaz de garantir a vitalidade urbana, a partir de um ponto de vista da prática cotidiana e da combinação de usos.

Alinhados com esse pensamento e como alternativa ao tipo de planejamento urbano corrente que produz "espaços estriados homogêneos" (Deleuze E GUATTARI, 1997), profissionais e iniciativas comunitárias buscam novas formas de reconstruir coletivamente os espaços urbanos em escala local, a partir das habilidades dos cidadãos em apresentar soluções para os desafios do cotidiano através da criatividade e dos recursos disponíveis. A investigação aborda ações micropolíticas como resistências nômades ou máquinas de guerra (DELEUZE E GUATTARI, 1997), anunciando um potencial de apropriação mais democrática do espaço público. O arquiteto Marcos Rosa tem documentado e analisado projetos que giram em torno da ideia de cooperação para propor um "Microplanejamento de práticas urbanas criativas" (2011), chamando a atenção para a importância de iniciativas locais na configuração da paisagem e a possibilidade de reestruturação urbana de baixo para cima, em que ações de resistência e valorização das especificidades locais podem ser conectadas estrategicamente e integradas ao planejamento urbano tradicional para a criação de modelos participativos mais democráticos (ROSA, 2011).

Nesse sentido, as questões do espaço público passam pela construção do público no espaço, com que o design pode contribuir a partir de uma perspectiva em escala mais humana, e com suas ferramentas e métodos que permitem reunir pessoas em torno de assuntos comuns e ações projetivas. O pesquisador Carl DiSalvo (2009) reflete sobre o papel do design na construção do público, partindo de um entendimento de público amplo, inclusivo e múltiplo, em que os produtos e processos de design devem contribuir para sua construção, tornando visíveis as questões locais a partir de um ambiente dialógico e crítico. Assim, o público poderia ser projetável através de "táticas de design", em oposição ao conceito de estratégia proposto por De Certeau (1994) enquanto estruturas de poder que estabelecem 
modos de ação. As táticas são os meios desenvolvidos para negociar estratégias que atendam a necessidades e desejos das pessoas envolvidas em determinado contexto. Para DiSalvo, essas táticas podem ser projetivas, como representação de possibilidades futuras através da construção de cenários, ou por traçado, em que formas projetuais revelam e tornam visíveis questões de interesse, expressam histórias, discursos e técnicas para dinamizar o conhecimento na direção do engajamento. Os diferentes tipos de táticas podem ser articulados de forma complementar e com percurso temporal, formando um campo público em torno das questões identificadas.

\section{0 potencial democrático das "coisas" de design}

Em "Democratic Design Experiments" (BINDER et al., 2015), Thomas Binder e outros autores exploram o potencial democrático da participação em processos de design, a partir da experiência teórica e prática do Participatory Design, que teve abordagem inicial voltada para a democracia no trabalho e depois estendida a questões de interesse público. Em resposta aos desafios propostos por Latour de “tornar as coisas públicas”, consideram que o Co-Design pode ter um papel importante na democratização da democracia, enquanto um processo contínuo de fazer, reparar e desfazer alinhamentos e conexões sócio-materiais, preparando as condições para discutir questões controversas no sentido de facilitar contradições, oposições e discordâncias por meio do engajamento (BINDER et al., 2015).

Carl DiSalvo (2010), por sua vez, apresenta o modelo de pluralismo agonístico para repensar a democracia e as possibilidades de ação de um design político. Diferente da noção hegemônica de democracia associada à busca de consenso e acesso à informação e aos procedimentos deliberativos, esta é baseada no conflito e disputa entre ideais, valores e crenças concorrentes. Uma das tarefas para apoiar e promover a democracia é criar espaços de disputa, diferença e dissenso e o design político deve funcionar para revelar e confrontar relações de poder através de seus objetos e processos, identificando novos discursos, práticas e bases para novas questões (DISALVO, 2010).

Nesse contexto, pesquisadores do Participatory Design escandinavo desenvolvem o conceito de "Design Things" com a proposição de reformular a prática do design e refletir sobre o que é projetado - oposição entre coisa e objeto como entidade de matéria - e como é projetado - espaços sócio-materiais que permitam lidar com a heterogeneidade de perspectivas e atores (BINDER et al., 2011). As "coisas de design" adquirem papel fundamental enquanto representações de assuntos de interesse e meios de gerar reuniões sócio-materiais para articular condições sociopolíticas (LATOUR, 2005). Assim, o público pode ser formado a partir do debate sobre a criação de coisas que ainda não existem, mas sobre as quais as pessoas se reúnem para discutir e construir coletivamente, a partir da dissonância 
de posições diversas. São "questões de interesse" controversas, em oposição à ideia de questões de fato como realidade única a ser alcançada; com que podemos trabalhar sem interromper o fluxo social, explorando a multiplicidade de interpretações e incertezas discutíveis, para que a "diversidade não seja prematuramente fechada por uma visão hegemônica" (LATOUR, 2012).

"Pensar sobre os artefatos em termos de design significa concebêlos cada vez menos como objetos modernistas e cada vez mais como "coisas". Usando minha linguagem: os artefatos estão se tornando concebíveis como conjuntos complexos de questões contraditórias (lembrando que esse é o sentido etimológico da palavra "thing" em inglês, bem como em outras línguas europeias). Quando as coisas são consideradas como bem ou mal elaboradas, elas não se apresentam mais como questões de fato. Assim, à medida que sua apresentação como questões de fato se enfraquece, seus lugares entre as muitas questões de interesse são fortalecidos." (LATOUR, 2014:6)

"Design things" está, portanto, associado a um lugar comum para negociar conflitos, discutir ideias e interesses diversos; um espaço com perspectivas heterogêneas de atores engajados na tentativa de resolver conflitos e controvérsias, em oposição ao consenso, possibilitando o surgimento de novas formas de pensar e se comportar, com abertura para interpretações inesperadas. Esta abordagem do design como um modo de investigação processual cria estratégias e táticas para serem transformadas através da performance de interação entre um coletivo de humanos e não humanos, sem a preocupação de cumprir etapas pré-definidas. São ferramentas e técnicas que agregam as pessoas para imaginar, discutir e analisar ideias; traduzem interesses em linguagem compartilhada para mediar questões e comunicar visões, criando espaço para diálogo e discussão; assumem um papel de mediação de uma investigação com objetivos relacionais abertos a interpretações (BJÖGVINSSON, 2012; KosKinEN, 2011; MANZINI, 2015).

Ainda nesse sentido, Gunn e Donovan (2012) sugerem a ideia dos "provótipos" como artefatos críticos facilitadores e catalisadores de atores, entre uma mistura de protótipo com provocação, cujo objetivo é instigar reflexões sobre as práticas existentes e possibilidades futuras, através de processos experimentais de imaginação coletiva. São considerados incompletos para construção conjunta, através de práticas projetuais colaborativas que estimulem o diálogo e facilitem a imaginação sobre as alternativas de desdobramento. Nesse processo, os designers abandonam parte do controle e se abrem ao inesperado, criando espaços de discussão e engajamento contínuo com as pessoas para pensar em diferentes formas de se abordar as questões sociais compartilhadas, em experiências projetuais de 
improvisação em campo intermediadas por esses artefatos de debate e visualização.

Ao encontro desses conceitos, Anastassakis e Szaniecki (2016) desenvolvem a noção de "dispositivos de conversação" enquanto experimentos de pesquisa e diálogo público no cenário urbano. Articulam o conceito de dispositivo de Foucault, como um conjunto de estratégias de relações de força que formam uma rede de conexões entre possibilidades e suas transformações; com o de conversação, como uma construção compartilhada de discursos possíveis, que difere da opinião formada por meio da comunicação. Propõem o uso de artefatos de visualização para construir processos abertos de engajamento e imaginação coletiva sobre visões possíveis para as questões do espaço urbano, formando uma estrutura multilateral, horizontal e transversal entre agentes heterogêneos com diferentes conhecimentos e práticas, em abordagem transdisciplinar.

Ao longo das investigações de mestrado e doutorado, tenho buscado explorar as "coisas de design", seus processos e ferramentas, como táticas e estratégias para a construção de públicos em torno de assuntos surgidos e elaborados a partir das interações contextuais em trabalho de campo. No projeto "Rio Comprido em Nós”, foram construídas ferramentas visuais como estímulo para as discussões e também como produto para dar visibilidade às questões de interesse, envolvendo as pessoas, suas motivações e redes.

\section{Rio Comprido em Nós}

A partir desse embasamento teórico apresentado anteriormente sobre o posicionamento político do design e possíveis articulações com o (espaço) público, busquei atuar em campo com experimentações metodológicas, assumindo o design como modo de pesquisa e suas ferramentas como "Design Things", com o objetivo de reunir diversidade de opiniões e desejos, estimular a troca através da mediação de possíveis debates entre essas diferenças, produzir espaços de engajamento e materializar os assuntos compartilhados.

O projeto foi desenvolvido no bairro do Rio Comprido, com o qual tenho uma longa relação pessoal. Localizado na área central da cidade do Rio de Janeiro, vive um abandono por parte do poder público, com realidade de intensa desigualdade social e concentração de pobreza, além da presença de uma cicatriz urbana representada pelo Viaduto Paulo de Frontin. A inquietação inicial da investigação tendia a projetos de apropriação e requalificação da área embaixo do viaduto, por ser um problema de impacto imediato na vida cotidiana dos moradores, em estado de abandono e degradação, mas também um marco simbólico na história do bairro e em sua configuração, visto que corta toda a sua extensão. Entretanto, optei por abrir o processo para caminhos além dos interesses pessoais, que pudessem ser gerados a partir da interação com os moradores e múltiplos atores da região. E, partindo da reflexão sobre o espaço público, acabei por estender o foco da 
investigação para as "questões de interesse" público, que emergiram desses encontros sócio-materiais.

Com presença constante no terreno e moradia no bairro, vida pessoal e pesquisa se misturaram, num processo de imersão e ideação em constante resposta e estímulo. A atividade projetual ancorou-se nas teorias e práticas do Design Anthropology (GUN E DONOVAN, 2012), campo emergente que conjuga as produções de conhecimento desse encontro interdisciplinar, através de um envolvimento comprometido com o contexto de pesquisa, posicionamento intervencionista e o desenvolvimento de ferramentas experimentais mediadoras que provoquem diálogos através da prática, para a co-criação de alternativas possíveis para o futuro. Nesse sentido, busquei atuar "em correspondência" (GATT E INGOLD, 2013) às dinâmicas locais, modificando o planejamento prévio das atividades a cada nova ideia, desafio e oportunidade, em função do tempo disposto e da interação com as pessoas. Táticas projetuais foram relacionadas em orientações temporais diferentes e complementares, buscando as origens das questões no passado, tornando-as visíveis no presente e projetando suas possíveis consequências no futuro, em articulação dinâmica e não linear.

Foi feita uma extensa pesquisa histórica para melhor compreensão sobre a formação territorial do bairro e suas relações sociais, bem como para conhecer acontecimentos e lugares que marcaram sua história. Realizei um mapeamento do lugar para identificar instituições, comércios e serviços do bairro; para observar seus fluxos, infraestrutura e utilização dos espaços; através de caminhadas, entrevistas e conversas, resultando na coleta de fotografias, vídeos, desenhos, diagramas e notas, reunidos num caderno de campo/projeto. Com intenção de ultrapassar a visão pessoal do lugar e conhecer outras perspectivas, foram realizadas entrevistas com moradores, estimuladas por uma ferramenta visual composta de um mapa a ser construído em conjunto com o participante, a partir das suas vivências, percepções e interesses. $\mathrm{O}$ dispositivo se mostrou um instrumento valioso, repleto de interpretações e novas informações a cada conversa. É composto por um pequeno guia de perguntas a fim de amarrar os interesses da investigação, mas mantendo uma abertura suficiente para captar novos assuntos surgidos do momento e da relação construída. Adesivos com ícones e cartões coloridos deram um suporte lúdico à interação, despertando assuntos não previstos, em variação contextual. 


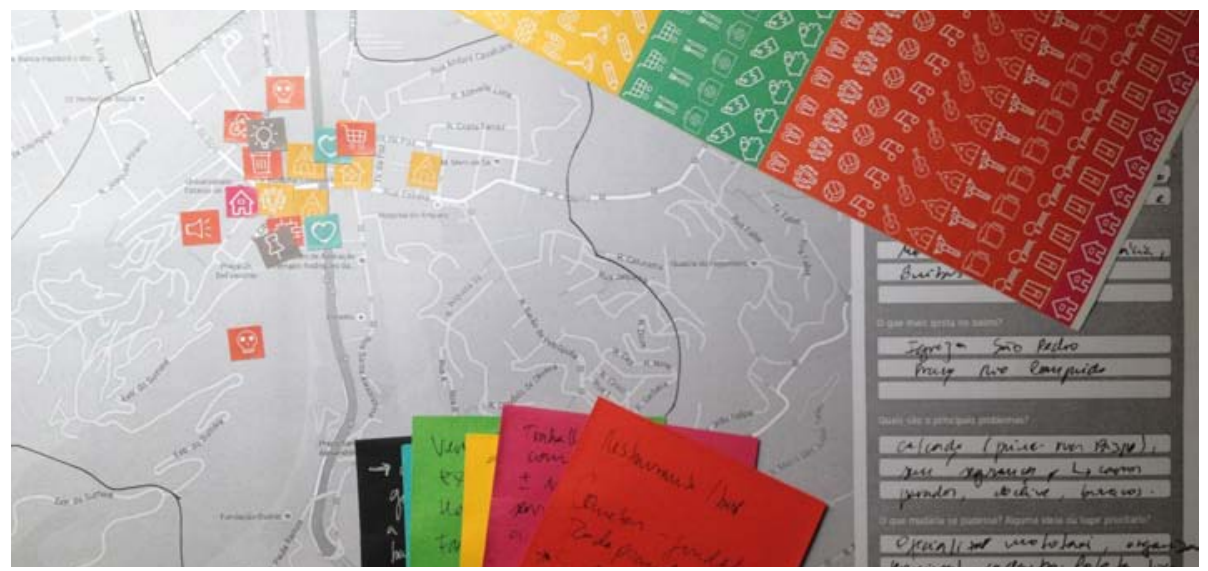

Figura 1. Ferramenta visual: mapa participado (fonte: da autora)

Algumas ações online foram realizadas para complementar as discussões, através de uma página no Facebook e um grupo de moradores e ex-moradores do bairro, ou pessoas com algum tipo de interesse pelo lugar, ampliando a rede de interações. Para isso, foram desenvolvidas outras ferramentas visuais de estímulo às conversas, que buscaram levantar novas questões ou aprofundar interesses já identificados. Essa atividade teve grande importância na organização dos assuntos de interesse da investigação, entre problemas, interesses e desejos, valores estruturais e históricos.
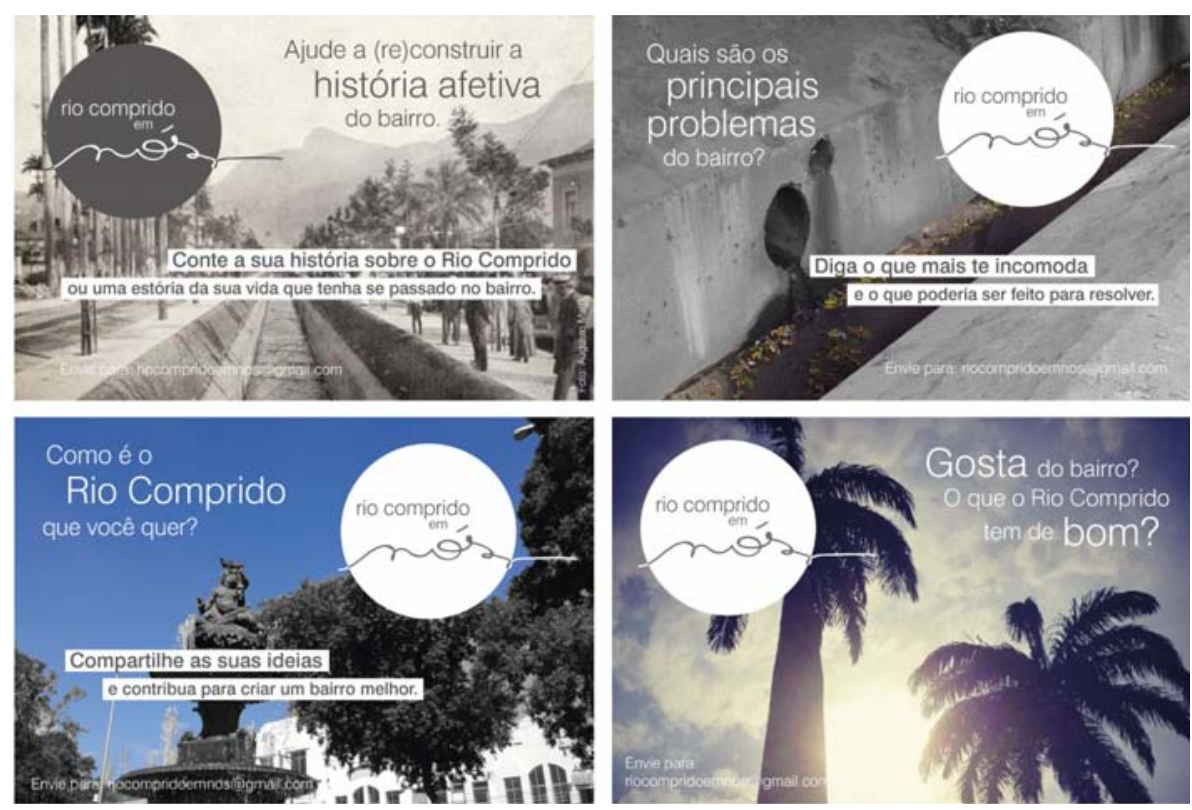

Figura 2. Ferramentas visuais: posts no Facebook (fonte: autora)

Durante todo o processo de pesquisa e diálogo com os moradores, foram levantados muitos dados e surgiram ideias acerca das possibilidades e oportunidades do que fazer para a melhoria da qualidade de vida no bairro. Para lidar com a imensa 
quantidade de informação recolhida, analisar os possíveis resultados e refletir sobre as ações seguintes, foi organizado um painel de visualização e classificação entre: ativos (históricos, lugares, pessoas, projetos), passivos (problemas prioritários, necessidades) e possibilidades para o futuro (ideias, desejos e oportunidades). Tal organização permitiu elencar aspectos como a memória afetiva e lugares de importância simbólica que poderiam ser valorizados, outros em abandono que demandavam cuidado prioritário, projetos e iniciativas de pessoas no bairro que poderiam ser potencializadas, manifestações culturais que alcançariam maior público com devida visibilidade.

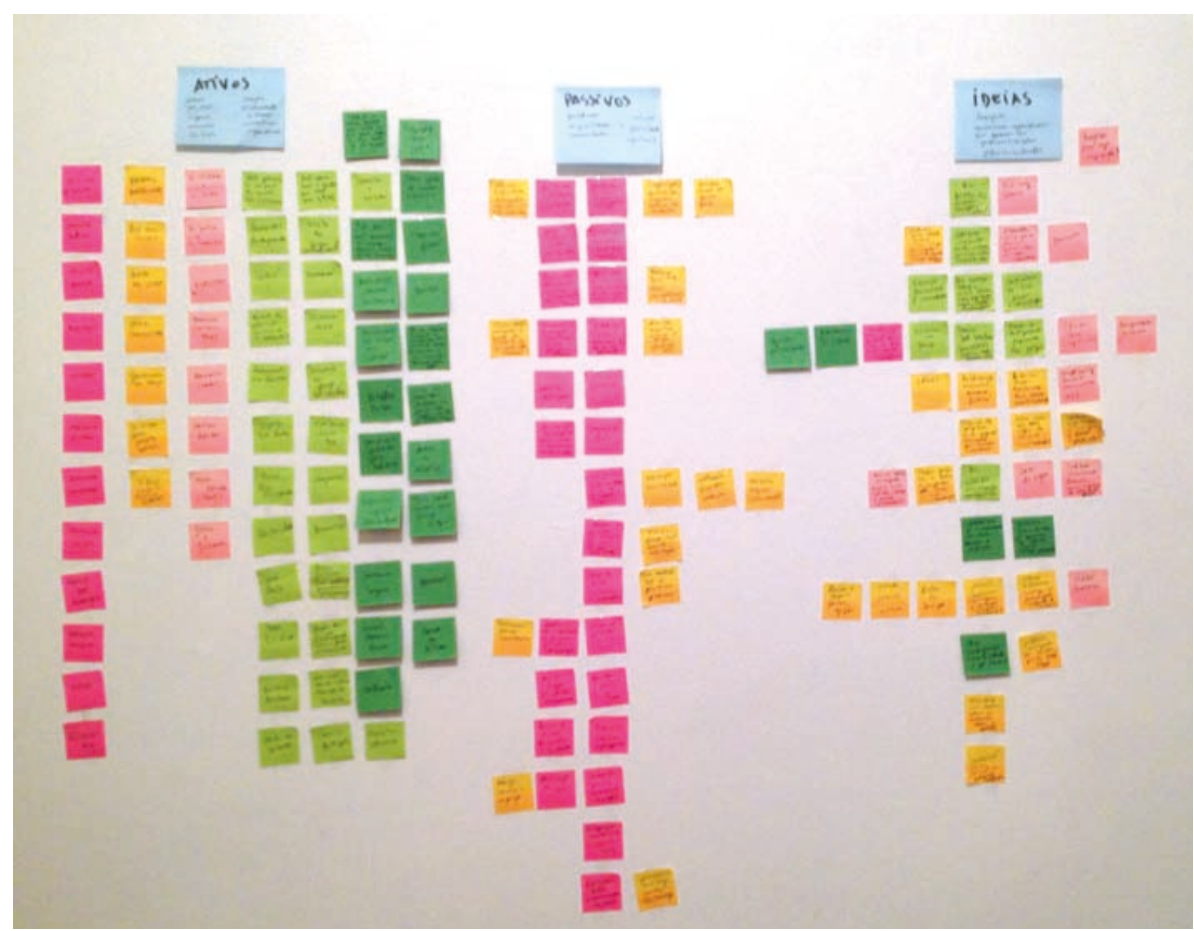

Figura 3. Painel de análise e classificação das "questões de interesse" (fonte: autora)

Todas essas informações podem ser interpretadas como "questões de interesse", sobre as quais residem opiniões diversas e possivelmente controversas. Tanto o bairro do Rio Comprido, como cada uma dessas questões, se abordadas enquanto foco de ação projetual, tem potencial de formar um campo público de debate, seja por meio de sua visibilidade, da revelação das relações de poder envolvidas, ou através da imaginação coletiva sobre as proposições futuras. As ferramentas de design ajudam a criar reuniões sócio-materiais de debate e disputa, identificando novos discursos e práticas para a construção coletiva.

No desenvolvimento do projeto, as questões de interesse foram identificadas e materializadas em novos produtos visuais, que poderiam posteriormente ganhar visibilidade e retornar à comunidade para novas interpretações e discussões. Alguns assuntos foram destacados: história e memória 
afetiva, transformadas em uma linha do tempo que compõe uma narrativa visual com fotografias históricas encontradas; lugares com importância histórica e simbólica, expostos em forma de cartão postal e organizados em um mapa como um roteiro para percurso exploratório; problemas prioritários, expressos em cartazes sobre dificuldades e necessidades identificadas; iniciativas locais, distribuídas em um jogo de cartas com projetos desenvolvidos no bairro e em outros lugares do mundo para estimular uma atividade interativa que estimule novas reflexões entre os moradores; cenários futuros, representados visualmente em um pequeno livreto como resultado da atividade projetiva de possíveis consequências futuras dos desejos e sonhos dos moradores.

Ao fim do processo, as peças desenvolvidas foram reunidas em uma publicação com múltiplas camadas e formatos, denotando a diversidade experimentada e descoberta durante a investigação, representando o Rio Comprido e os seus "nós". Os produtos visuais podem ter utilidades públicas diferentes e isoladas, ou funcionar como insumo para outras ações e projetos no bairro.

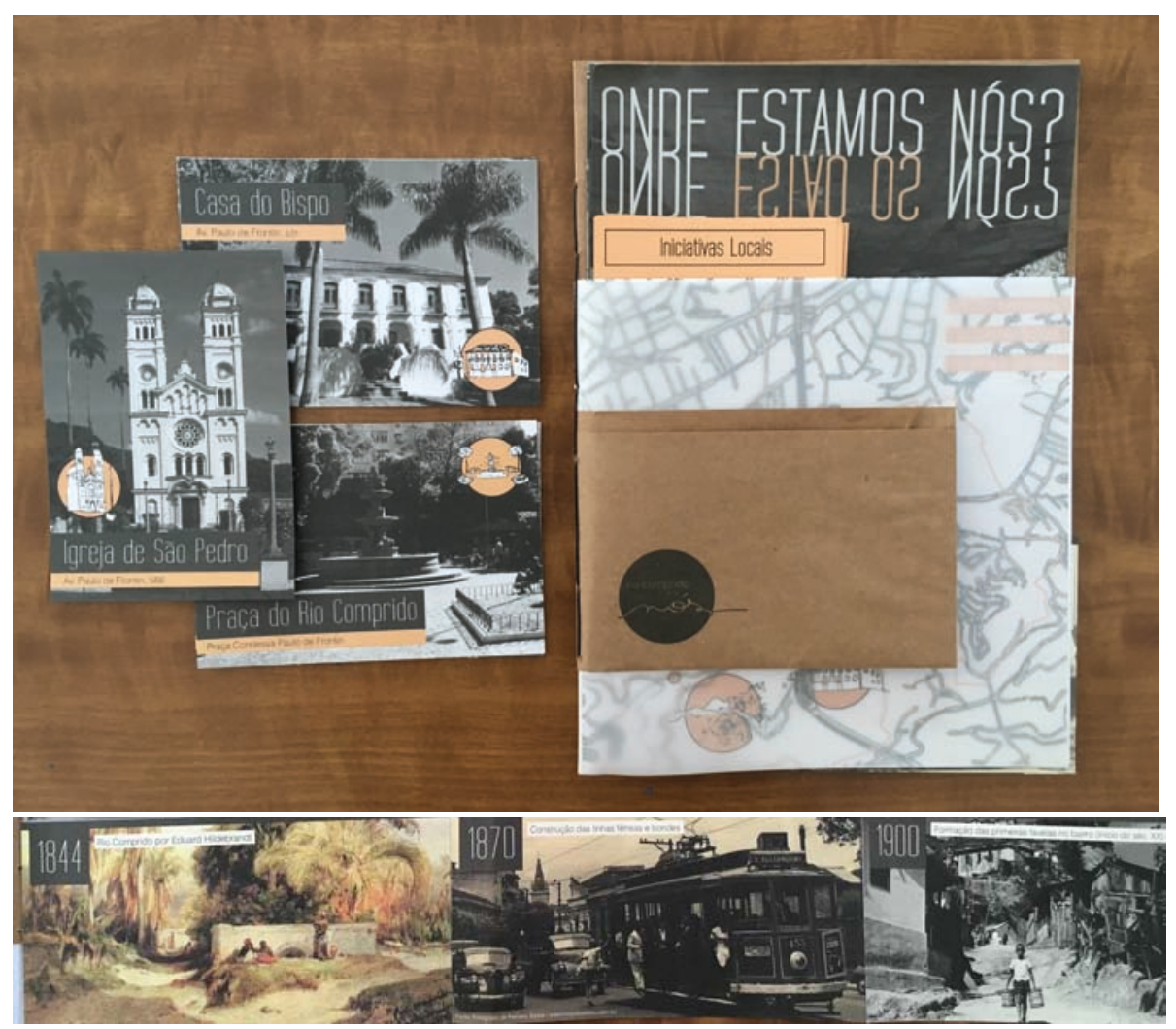




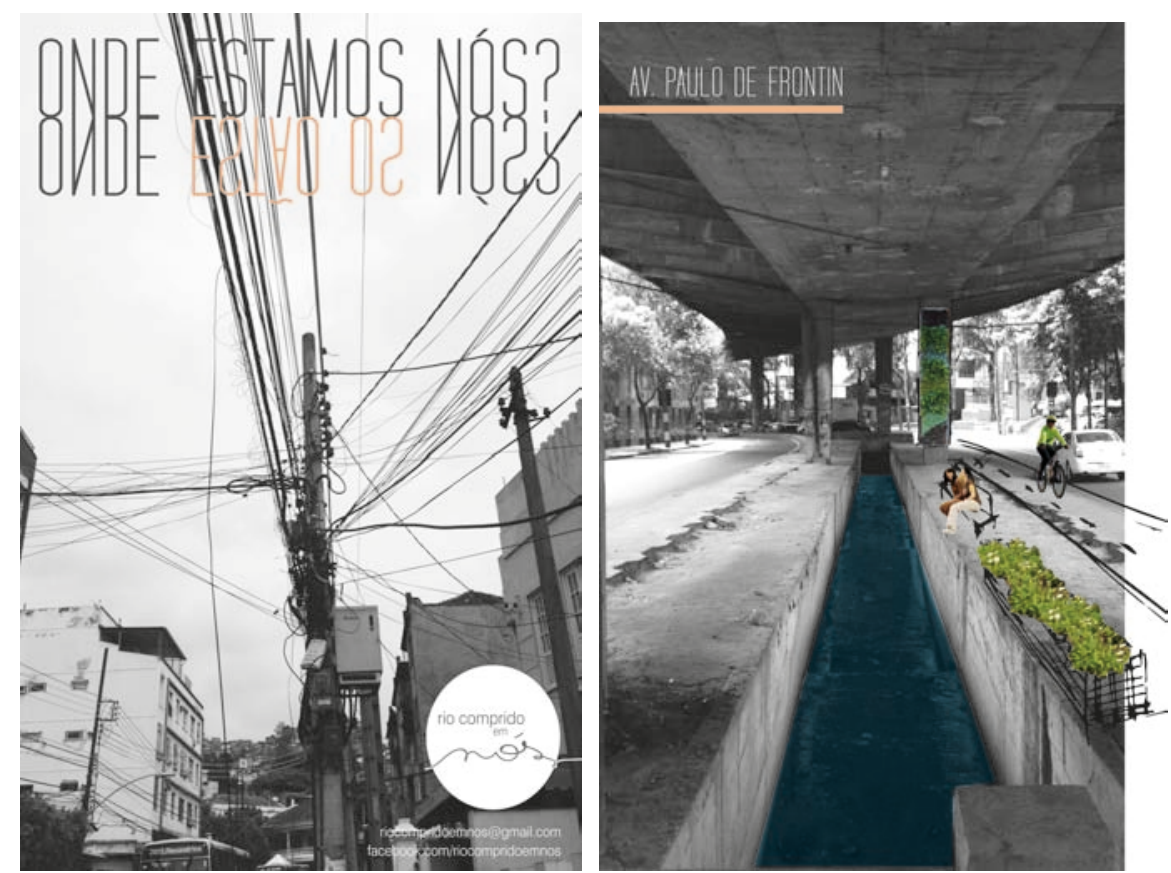

Figura 4. Parte da publicação final com produtos visuais desenvolvidos (fonte: autora)

\section{Considerações finais}

Do espaço público urbano e sua produção capitalista, com planejamento homogêneo e excludente, que tenta silenciar a diferença e intensifica desigualdades socioeconômicas; à reivindicação pelo direito à cidade, por espaços democráticos heterogêneos, de debate e disputa, do dissenso e do pluralismo agonístico. O artigo identifica a potencialidade do design para explorar suas ferramentas e métodos como associações possíveis entre humanos e "coisas", construir lugares de interação e diálogo para criar alternativas de forma colaborativa, a partir da diferença e das controvérsias, em oposição a uma concordância uniforme e distante da complexidade das questões vivenciadas. Com um posicionamento político em torno das "questões de interesse", o design pode ajudar a criar um campo público inclusivo e múltiplo, confrontar relações de poder e identificar outros discursos e práticas, com abertura para novos modos de vida.

A experiência de campo explorou parte do potencial de "Design Things" como espaços heterogêneos de discussão e imaginação coletiva, como recursos para reunir pessoas em torno de assuntos de interesse, mapear questões, materializar visões, incentivar discussões, facilitar contradições, estimular a reflexão e o engajamento. E a investigação em curso avança sobre possíveis desdobramentos dessas "coisas" e processos do design que possam alimentar reflexões e discussões sobre a construção do público nos espaços das cidades, contribuir para o planejamento urbano e a criação de políticas públicas mais democráticas e condizentes com as necessidades e desejos das pessoas. 


\section{Referências}

ANASTASSAKIS, Zoy; SZANIECKI, Barbara. Conversation dispositifs: towards a transdisciplinary design anthropological approach. In Design Anthropological Futures. Bloomsbury Academic, 2016.

BINDER, Thomas, et al. Design Things. The MIT Press, 2011.

BINDER, Thomas, et al. Democratic design experiments: between parliament and laboratory. CoDesign 11.3-4: 152-165, 2015.

BJÖGVINSSON, Erling; EHN, Pelle; HILLGREN, Per-Anders. Design things and design thinking: Contemporary participatory design challenges. Design Issues 28.3: 101-116, 2012.

DE CERTEAU, Michel. A invenção do cotidiano. Vozes, 1994.

DELEUZE, Gilles; GUATTARI, Félix. Tratado de Nomadologia: a máquina de guerra. Mil platôs: capitalismo e esquizofrenia. Pelbart PP, Caiafa J, tradutores. Rio de Janeiro: Ed 34 (1997): 11-110.

DISALVO, Carl. Design and the Construction of Publics. Design issues 25.1 : 48$63,2009$.

DISALVO, Carl. Design, democracy and agonistic pluralism. Proceedings of the design research society conference. 2010 .

FOUCAULT, Michel. Microfísica do poder. Organização e tradução de Roberto Machado. Rio de Janeiro: Edições Graal 4, 1979.

GATT, Caroline; INGOLD, Tim. From description to Correspondence: Anthropology in Real Time. In: Design Anthropology: Theorie and Practice. Ed: Gunn, Wendy; Otto, Ton; Smith, Rachel. p. 175-198. Bloosmbury, 2013.

GUNN, Wendy; DONOVAN, Jared. (Eds.) Design and Anthropology: Anthropological studies of creativity and perception. London: Ashgate, 2012.

HARVEY, David. Cidades rebeldes: do direito à cidade à revolução urbana. São Paulo: Martins Fontes, 2014. 
JACOBS, Jane. Morte e vida de grandes cidades. Martins Fontes, 2000.

LATOUR, Bruno. From realpolitik to dingpolitik. Making things public: Atmospheres of democracy: 14-44, 2005.

LATOUR, Bruno. Reagregando o social: uma introdução à teoria do ator-rede. Salvador, Bauru: Edufba e Edusc, 2012.

LATOUR, Bruno. Um Prometeu cauteloso?: alguns passos rumo a uma filosofia do design (com especial atenção a Peter Slotedijk). Agitprop: revista brasileira de design, São Paulo, v. 6, n. 58, jul./ago. [2008] 2014.

LEFEBVRE, Henri. A produção do espaço. Trad. Doralice Barros Pereira e Sérgio Martins (do original: La production de l'espace. 4e éd. Paris: Éditions Anthropos), [1974] 2000 .

LEFEBVRE, Henri. O direito à cidade. Centauro Editora, 2008.

MAGNANI, José Guilherme Cantor. De perto e de dentro: notas para uma etnografia urbana. Revista Brasileira de Ciências Sociais 17.49: 11-29, 2002.

MANZINI, Ezio. Design When Everybody Designs - An Introduction to Design for Social Innovation. London: The MIT Press, 2015.

REYES, Paulo. Construção de cenários em design: o papel da imagem e do tempo. Artigo apresentado no 9o Congresso de Pesquisa e Desenvolvimento em Design (P\&D Design). São Paulo, 2010.

ROSA, Marcos; ed. Microplanejamento de práticas urbanas criativas. Microplanning urban creative practices. São Paulo. Ed. De Cultura, 2011.

SILVANO, Filomena. Antropologia do espaço. Lisboa: Assírio \& Alvim, 2010.

VAINER, Carlos. Pátria, empresa e mercadoria - Notas sobre a estratégia discursiva do Planejamento Estratégico Urbano. In A Cidade do Pensamento Único. Editora Vozes, 2000. 


\section{Como citar}

COSTARD, Mariana. "Rio Comprido em Nós": do espaço público à construção do público por meio do design. Arcos Design. Rio de Janeiro: PPD ESDI - UERJ. Edição Especial Outubro 2017. pp. 147-162.

Disponível em: [http://www.e-publicacoes.uerj.br/index.php/ arcosdesign]

DOI: $10.12957 /$ arcosdesign.2017.30946

\section{(c) (1) (8)(2)}

A Revista Arcos Design está licenciada sob uma licença Creative Commons Atribuição - Não Comercial - Compartilha Igual 3.0 Não Adaptada. 